\title{
Planejamento estratégico no setor público: uma experiência no Palácio do Planalto
}

\section{RSP}

Revista do

Serviço

Público

Ano 53

Número 4

Out-Dez 2002

\author{
Gileno Fernandes Marcelino
}

\section{Introdução}

Este artigo descreve um processo de planejamento estratégico de um órgão do Palácio do Planalto, a Secretaria-Geral da Presidência da República (SGPR/PR), e do seu braço executivo, a Diretoria-Geral de Administração (DGA). A utilização desse processo na SGPR iniciou-se, em 1995, com a realização do I e II Encontros de Planejamento e Administração Estratégica, cujos propósitos eram identificar a missão e os objetivos, formular as estratégias e estabelecer programas e projetos prioritários para o quadriênio 1995-1998. Após a realização dos dois primeiros encontros de planejamento, foi também desenvolvido um processo de reestruturação administrativa da Diretoria-Geral de Administração, órgão executor e principal componente da SGPR, que reduziu substancialmente sua estrutura e custos burocráticos. É desnecessário destacar o caráter pioneiro e a importância desse processo, uma vez que a Presidência da República é o centro estratégico de decisões do Poder Executivo.

O secretário-geral da Presidência da República decidiu iniciar sua gestão, em 1995, construindo uma visão do futuro, a partir da reflexão do corpo de assessores e de dirigentes dos órgãos integrantes da estrutura da SGPR, de modo a fixar diretrizes de ação e priorizar programas e projetos estratégicos, a partir da missão e dos objetivos definidos, tendo como horizonte de planejamento o período correspondente ao primeiro mandato do governo Fernando Henrique Cardoso. A DGA, entendendo ser o planejamento e a administração estratégica ferramenta adequada de gestão e considerando as diretrizes definidas nos primeiros encontros, adotou essa metodologia para desenvolver, acompanhar e avaliar suas atividades.

\footnotetext{
Gileno Fernandes Marcelino é professor da Universidade de Brasília (UnB); professor visitante da J.L.Kellogg Graduate School of Management da Northwestern University; professor associado da Universidade de São Paulo; consultor de processos de reestruturação administrativa e planejamento estratégico em organizações públicas e privadas; e, atualmente, é diretor da Faculdade de Estudos Sociais da UnB.

Contato: gmarcel@ solar.com.br
} 


\section{Breve histórico}

O I Encontro de Planejamento e Administração Estratégica foi realizado no Centro de Formação do Banco do Brasil, nos dias 31 de março e $1^{\circ}$ de abril de 1995. Um mês depois, em 5 e 6 de maio, foi realizado o II Encontro da SGPR. A divisão em dois encontros foi necessária não somente pelo grande número de participantes envolvidos, como também pelo agrupamento dos dirigentes de mais alto nível (DAS 4 a DAS 6) no primeiro encontro e de dirigentes de nível intermediário (DAS 2 a DAS 3) no segundo encontro. A proposta metodológica sugeria encontros anuais para balanço das atividades desenvolvidas e revisão anual do processo.

No período de 17 a 20 de setembro de 1996, mais de um ano após os primeiros encontros, foi realizado o III Encontro de Planejamento e Administração Estratégica, desta vez com a participação de todos os dirigentes da DGA, para fazer um balanço dos resultados do processo até aquela data e rever a missão e os objetivos da SGPR, além de listar programas, projetos, metas e ações necessários à modernização administrativa e tecnológica da DGA. Nesse terceiro encontro, foram ainda analisados os ambientes externo (oportunidades e ameaças) e interno (pontos fortes e fracos) da Diretoria-Geral.

É importante ressaltar que, a partir do terceiro, os encontros anuais foram subdivididos em reuniões por departamento da DGA, em um total de seis reuniões, para compatibilizar objetivos, programas e metas gerais e setoriais da DGA. Ainda em 1996, foi realizado, no período de 14 de outubro a 8 de novembro, o IV Encontro de Planejamento e Administração Estratégica, com um caráter todo especial, uma vez que, pela primeira vez, dele participaram, além dos dirigentes da DGA, os chefes de seção e seus substitutos e, até mesmo, líderes informais de grupos. Essa participação permitiu que os resultados do encontro refletissem a realidade organizacional da DGA e possibilitou que todos os participantes se comprometessem com a implantação das decisões.

Em 1997, foi realizado o V Encontro de Planejamento e Administração Estratégica, no período de 23 de outubro a 21 de novembro, consolidando, ainda mais, o processo e o compromisso dos servidores com a administração. Assim como ocorreu com os três eventos anteriores, o VI Encontro de Planejamento e Administração Estratégica, realizado no período de de 15 de novembro a 10 de dezembro de 1998, foi subdividido em seis reuniões, com toda a equipe, e trouxe como novidade a implementação da sistematização dos programas e projetos já existentes, vinculados, de forma direta, com o orçamento da Presidência da República. 
A seguir, de forma resumida, encontram-se demonstrados o comprometimento e o engajamento dos servidores da DGA/SGPR com o processo de planejamento e administração estratégica no período 1995-1998.

\section{Quadro 1: Comprometimento e engajamento dos servidores da DGA/SGPR}

\begin{tabular}{|c|c|c|c|c|c|c|}
\hline Ano & Encontros & Participantes & Programas & Projetos & Metas & $\%$ \\
\hline 1995 & I & 26 & - & - & - & - \\
\hline 1995 & II & 36 & 8 & 26 & - & 76,4 \\
\hline 1996 & III & 26 & 8 & 38 & 64 & 81,2 \\
\hline 1996 & IV & 156 & 8 & 44 & 146 & 81,2 \\
\hline 1997 & V & 132 & 8 & 45 & 131 & 89,7 \\
\hline 1998 & VI & 127 & 4 & 13 & 140 & 91,3 \\
\hline
\end{tabular}

A última coluna da tabela $(\%)$ corresponde ao percentual de metas, projetos e programas atingidos (cumpridos) durante o ano de planejamento.

\section{O que é a DGA/SGPR?}

A DGA é subordinada à SGPR, fazendo parte, portanto, do complexo político-administrativo da Presidência da República. Esse complexo era composto, no período estudado, por:

- Presidência da República - aqui entendida apenas pelo próprio Presidente da República, principal cliente da SGPR/DGA;

- Casa Civil - responsável pela coordenação das ações políticas dos demais ministérios, das câmaras setoriais e do Programa Comunidade Solidária;

- Casa Militar — responsável pela articulação com os ministérios militares, pela segurança pessoal do presidente da República, do vicepresidente e dos respectivos familiares, pelas atividades de inteligência e pelas políticas de prevenção e combate às drogas;

- Secretaria de Assuntos Estratégicos (SAE) - responsável pela coordenação das atividades estratégicas do governo, como o Projeto Sivam, o Projeto Calha Norte, o programa nuclear, o programa espacial, além da elaboração de estudos e cenários sobre as tendências políticas, econômicas, sociais, de globalização, etc. para o próximo milênio;

- Secretaria de Comunicação Social - responsável pela coordenação das atividades de comunicação social de todos os órgãos da administração pública, direta, autárquica e fundacional, pela gestão do contrato com a Associação de Comunicação Educativa Roquete Pinto (Acerp) e pela supervisão da Radiobrás; e 
- SGPR — responsável pelas atividades de gestão político-administrativa do complexo da Presidência da República, concentrando as atividades da Ajudância-de-Ordem, do Gabinete Pessoal, do Controle Interno, da Documentação Histórica, do Cerimonial, da Assessoria Especial, da Modernização e Informática e da DGA. ${ }^{1}$

Fruto de decisão política do governo, o complexo político-administrativo denominado Presidência da República é gerido por meio do conceito básico de "órgão essencial". Esse conceito explicita que determinada atividade ou serviço deve ser realizado apenas pela unidade que detenha a excelência na execução daquela tarefa, evitando duplicação de esforços. Por exemplo: apenas a Subchefia para Assuntos Jurídicos da Casa Civil responde pelo assessoramento nessa área, atendendo todas as necessidades jurídicas dos órgãos do complexo.

Nesse contexto, a DGA é o único órgão de gestão administrativa do complexo da Presidência da República. Regimentalmente, a DGA tem por finalidade planejar, coordenar, supervisionar, controlar, avaliar, promover e orientar a execução de ações e atividades pertinentes a: administração e desenvolvimento de recursos humanos, assistência à saúde, orçamento e finanças, material, patrimônio, compras, contratações, administração de convênios, transportes, subsistência, documentação, comunicação administrativa, expediente e arquivo, biblioteca, administração de recursos de telecomunicações e informática, administração de residências oficiais e manutenção de equipamentos, edifícios públicos e infra-estrutura predial, apoio a viagens do presidente e serviços gerais em apoio administrativo aos órgãos essenciais da Presidência da República.

Essa concentração de atividades permitiu a implementação de processos de racionalização de rotinas e procedimentos, ao mesmo tempo em que acumulou uma série de atividades que não estavam previstas inicialmente. Entre estas, cabe destacar o acompanhamento dos convênios referentes aos projetos controlados pela SAE e a gestão das liberações e controle de fluxo de recursos referentes ao Sivam, aos programas espacial e nuclear. Nesse contexto, o patamar de controle e liberação de recursos orçamentários passou de uma ordem de $\mathrm{R} \$ 40$ milhões para $\mathrm{R} \$ 2$ bilhões, só com a inclusão do Projeto Sivam.

É importante mencionar que a estrutura da DGA resultou de um processo de reestruturação administrativa realizado ainda em 1995, em complementação ao processo de planejamento e administração estratégica.

Este estudo pretende descrever os processos de mudança e gestão estratégica desenvolvidos no âmbito da DGA e de suas unidades organizacionais, considerando o período 1995-1998, e engloba não somente as atividades executadas, mas, principalmente, as dificuldades superadas e a perfeita consonância dessas atividades com o processo de planejamento e administração estratégica. 
Metodologia dos processos

A metodologia adotada para a realização dos "Encontros de Planejamento e Administração Estratégica da DGA/SGPR" consistiu na definição da missão e dos objetivos, na análise dos ambientes interno e externo, na definição de diretrizes estratégicas e no desenvolvimento de programas, projetos, metas e ações que foram implementados no período de 1995 a 1998. E, como dizem os teóricos desde Chandler, "a estrutura segue a estratégia". Assim, o processo implicou reestruturação administrativa da DGA, com substancial redução dos seus custos burocráticos.

A metodologia, especialmente desenvolvida para o setor público brasileiro pelo Professor Gileno Fernandes Marcelino, a partir da literatura e da prática do planejamento e da administração estratégica, tem como pressupostos básicos o incentivo à criatividade individual, a participação e o comprometimento dos agentes envolvidos e a busca do consenso do grupo. Para tanto, requer homogeneização de percepções quanto aos conceitos utilizados, definição clara das tarefas e observância do tempo estabelecido para cada etapa.

Operacionalmente, essa metodologia é desenvolvida em três momentos distintos:

a) no primeiro momento, os participantes utilizam a técnica de brain-writing, trabalhando individualmente, com formulários previamente estruturados, gerando idéias por escrito; é uma técnica de grupo nominal, sem possibilidade de interação verbal, para que não se iniba a geração de idéias;

b) no segundo momento, o grupo nominal se transforma em grupo real de trabalho, no qual as idéias são discutidas em busca do consenso do grupo, utilizando as técnicas tradicionais de dinâmica de grupo; e

c) o terceiro momento acontece no grande grupo (plenária), por meio do debate e consenso sobre o tema, tendo como base as contribuições dos pequenos grupos.

O brain-writing é uma técnica de geração de idéias, utilizando grupos nominais. As vantagens dessa técnica são as seguintes:

a) separar a fase de geração de idéia da fase de crítica e seleção da idéia;

b) possibilitar que todos os integrantes do grupo participem ativamente, uma vez que preenchem formulários previamente estruturados e trocam esses formulários entre si; e

c) documentar as idéias dos participantes, na medida em que todas são propostas por escrito nos formulários, que são recolhidos pela coordenação. 
A metodologia é, normalmente, desenvolvida de acordo com as seguintes etapas:

- Preparação: na fase de preparação, é solicitada aos participantes a leitura de documentos sobre o órgão e textos sobre assuntos tratados no encontro, com objetivo de permitir a formação de conhecimentos e subsidiar a definição do plano de trabalho de forma realista e fundamentada;

- Apresentação dos objetivos, conceitos e metodologia: o I Encontro foi inaugurado pelo secretário-geral da Presidência da República e os demais tiveram sempre a participação integral do diretor-geral de Administração. Em seguida, foram realizadas pelo facilitador exposições em plenária sobre os conceitos utilizados, os objetivos do evento, a metodologia do planejamento e administração estratégica e a técnica brainwriting;

- Desenvolvimento dos trabalhos em pequenos grupos e em plenária: a partir dessa exposição inicial, que visava homogeneizar os conhecimentos e proporcionar uma linguagem comum aos participantes, os trabalhos foram realizados em pequenos grupos, tendo como objetivos:

a) obter contribuições individuais sobre a missão e os objetivos da DGA/SGPR e/ou dos departamentos, os aspectos do ambiente interno e externo e as estratégias a serem desenvolvidas; e

b) promover discussão sobre os temas citados, com vistas ao consenso do pequeno grupo.

Os pequenos grupos eram compostos por sete pessoas, no máximo, trabalhavam em salas separadas, especialmente preparadas, e contavam com a orientação do facilitador do processo. As contribuições do pequeno grupo eram registradas e levadas à plenária. A plenária, então, reunia todos os participantes do encontro, coordenada por um consultor, oportunidade em que as contribuições eram apresentadas pelos relatores dos pequenos grupos para discussão, com vistas ao consenso.

Dessa forma, foram definidos em plenária a missão, os objetivos, as oportunidades e ameaças, os pontos fortes e fracos, as diretrizes estratégicas e os programas e projetos que deveriam ser implementados no período de 1995 a 1998. Os programas e projetos aprovados em plenária eram posteriormente detalhados, internamente, pelas equipes de trabalho; $\mathrm{e}$

- Continuidade do processo: ao final dos encontros, os participantes eram orientados para que disseminassem os resultados do evento internamente em suas unidades, com a finalidade de envolvimento e comprometimento dos responsáveis pelos projetos definidos e aprovados em plenária, especialmente na ocasião do seu detalhamento e da sua execução.

Visando ao acompanhamento e à avaliação da execução do plano de trabalho, sugeriu-se o cadastramento dos programas e projetos de desenvolvimento por meio da utilização, desde 1995, de um software específico, 
o MS Project, de forma a permitir o registro de informações relativas à sua execução e a emissão de relatórios gerenciais. Complementarmente, sugeriu-se a realização de reuniões periódicas com dirigentes e técnicos, com o objetivo de nivelar informações e redirecionar ações. O diretor-geral de Administração, desde 1996, passou a reunir mensalmente sua equipe de dirigentes (adjuntos e chefes de departamentos) para acompanhar a evolução dos programas e projetos e fazer as necessárias correções.

"A burocracia vive em um ambiente estável e diferenciado. Uma estrutura piramidal de autoridade, com o poder concentrado nas mãos de poucos com o conhecimento e recursos para controlar uma empresa era um arranjo social perfeito para tarefas rotineiras. Contudo o ambiente mudou de tal maneira que tornou esse mecanismo problemático. A estabilidade desapareceu." (Bennis, apud Marcelino, 1997).

De acordo com Warren Bennis, a burocracia funciona adequadamente em um ambiente estável e diferenciado.

Lawrence \& Lorsch aceitam a hipótese básica de que a eficácia de formas organizacionais depende do grau de estabilidade do ambiente organizacional. Eles levantaram a hipótese de que, se o ambiente é estável, a organização pode obter informações sobre o seu ambiente com um sistema organizacional altamente estruturado e específico, em relação a regras, deveres, padrões de autoridade, papéis, processos de tomada de decisão e canais de comunicação (a burocracia). Onde o ambiente é instável, o sistema estrutural da organização deve ser menos rígido para obter informações adequadas sobre o ambiente.

Lawrence \& Lorsch sugeriram um modelo de diferenciação e integração organizacional baseado na instabilidade do ambiente. A diferenciação visa dar aos subsistemas da organização a liberdade para adaptar suas estruturas e processos às circunstâncias do ambiente que elas enfrentam. A integração visa garantir um funcionamento unificado e coerente da organização como contrapartida ou balanceamento da diferenciação.

Lawrence \& Lorsch nos revelam ainda dois aspectos da integração organizacional: o primeiro é que cabe à organização determinar que subsistemas devem trabalhar juntos; o segundo aspecto é que a organização determina como eles devem se integrar. No caso da DGA, foram feitos levantamentos na primeira fase do processo de reestruturação, com o objetivo de detalhar funções, disfunções, estruturas organizacionais e a validação das funções identificadas, analisar os dados e elaborar uma proposta de novo modelo organizacional estrutural, funcional e hierárquico. 


\section{O processo de planejamento e administração estratégica}

Ao assumir o poder em janeiro de 1995, o novo governo tinha uma clara intenção de reformar o Estado no Brasil. Portanto, nada melhor do que começar pelo próprio Palácio do Planalto, implantando uma administração profissional que suprisse as deficiências estruturais, já identificadas na administração do Palácio. As premissas básicas desse processo eram as ênfases na participação e no desenvolvimento de recursos humanos, na racionalização dos processos e estruturas e na otimização da administração da informação.

Assim, ao tomar a decisão de desenvolver e implantar um processo de planejamento e administração estratégica na SGPR, seu dirigente buscava uma visão geral e unificada de projetos e metas, sinergia nas ações e atividades dos órgãos componentes da SGPR, aumento do engajamento e viabilização da gerência participativa, além de objetivos como otimizar os recursos, tornar eficaz o controle dos processos e universalizar o acesso às informações.

O I Encontro de Planejamento e Administração Estratégica contou com a presença do secretário-geral e a participação da alta gerência. Nesse encontro, foram identificados a missão, os objetivos, as oportunidades, as ameaças e os pontos fortes e fracos, além de serem estabelecidas diretrizes estratégicas para o desenvolvimento da SGPR até 1998. Assim, identificou-se como missão da SGPR em 1995: "A Secretaria-Geral tem como missão prestar, com eficiência, assessoramento e apoio técnicoadministrativo ao presidente e aos órgãos essenciais da Presidência para o desempenho eficaz de suas atividades".

O segundo encontro com a participação dos níveis táticos e operacionais da SGPR e da DGA, definiu programas e projetos estratégicos. Dentre os programas destacavam-se os de recursos humanos, modernização administrativa, modernização de equipamentos, desregulamentação da legislação, melhoria das instalações prediais, proteção às informações sensíveis, informatização e planejamento e administração estratégica, para garantir a continuidade do processo.

A partir do terceiro encontro e de suas reuniões setoriais de, desenvolvidas especificamente para a DGA, definiu-se uma missão específica para a DGA: "A missão da Diretoria-Geral de Administração é executar, com excelência, o apoio técnico-administrativo à Secretaria-Geral da Presidência da República para o desempenho eficaz de suas atividades".

O quarto encontro, realizado ainda no ano de 1996, teve um caráter todo especial, uma vez que, pela primeira vez, dele participaram, ao lado dos dirigentes da DGA, os chefes de seção e seus substitutos, além de líderes de grupo. Essa participação permitiu que os resultados do encontro 
refletissem a realidade, não só do ponto de vista dos dirigentes, mas também daqueles que se encontravam na linha de frente das atividades, e, especialmente, legitimou o processo, firmando um compromisso entre a administração, os seus líderes e os seus liderados na busca da consecução dos programas, dos projetos, das metas e das ações, exaustivamente discutidas e consensualmente aprovadas.

Mas foi a partir de 1997, após dois anos de implementação do planejamento estratégico, que houve uma mudança no processo, com a consolidação da chamada gestão estratégica na DGA/SGPR. No período, houve uma transformação substantiva do processo de simples formulação de estratégias (planejamento estratégico) para a adoção do pensamento estratégico e dos conceitos modernos de estratégia (administração Estratégica).

A participação efetiva dos diversos níveis e camadas da pirâmide hierárquica da administração nesse processo contribuiu para a mudança de cultura, que se refletiu na melhoria da qualidade dos resultados, na redução de custos, na busca da excelência, no aumento da capacitação gerencial, no trabalho em equipe e na melhor utilização dos recursos humanos, materiais e financeiros da DGA.

Com o processo de administração estratégica implantado, em 1996, na DGA, o índice de realização de metas, projetos e programas já atingia 81,2\% do programado. Em 1997, foi realizado o V Encontro de Planejamento e Administração Estratégica, consolidando ainda mais o processo e o compromisso com a administração. Nesse ano, foi também desenvolvida uma reciclagem dos dirigentes da DGA para a utilização da ferramenta, moderna, de acompanhamento e avaliação de programas e projetos, o $M S$ Project, software que possibilitou acompanhar e avaliar as atividades programadas e desenvolvidas. Isso permitiu um salto qualitativo e um novo ganho no desenvolvimento das atividades do processo, passando a DGA a cumprir, em 1998, 91,3\% das suas metas, de seus projetos e programas.

A mensuração desses indicadores proposta no processo de planejamento e administração estratégica, como metodologia de acompanhamento, era realizada por meio de reuniões mensais com o diretor-geral, com os chefes de departamento e assessores, nas quais se avaliavam o ocorrido, as razões dos eventuais atrasos, as mudanças de prioridades ou a necessidade de rever ações em decorrência de contingenciamento orçamentário.

Por último, cumprindo o originalmente programado em 1995, realizou-se, após as eleições presidenciais de 1998, o VI Encontro de Planejamento e Administração Estratégica, que trouxe como novidades um maior agrupamento de programas e projetos e a implementação da vinculação direta dos programas e projetos já existentes com o orçamento da Presidência da República.

Acompanhando o desenvolvimento e amadurecimento do processo, a nova missão da DGA, em 1998, passou a ser a seguinte: “A missão da 
Diretoria-Geral de Administração é planejar, coordenar e executar, com excelência, as atividades de apoio técnico-administrativo de responsabilidade da Secretaria-Geral da Presidência da República", missão esta que facilitou sua transferência para o âmbito da Casa Civil.

É importante relembrar que, desde julho de 1995, como complemento indispensável ao processo de planejamento e administração estratégica, desenvolveu-se um programa de qualidade total, depois transformado em um dos oito programas, que mobilizou grupos de trabalho e comitês de qualidade, responsáveis por melhorias visíveis e uma cultura de aperfeiçoamento contínuo nas atividades da DGA.

\section{Diferenciação e integração: o processo de reestruturação administrativa}

No capítulo "Diferenciação e integração: o conceito de adaptabilidade organizacional" do livro Descentralização em ciência e tecnologia (Marcelino, 1985), o autor define alguns parâmetros para um tamanho adequado de organização, em que cada forma, centralizada ou descentralizada, tem vários níveis organizacionais, que correspondem ao grau de responsabilidade e perspectiva, envolvidos em cada nível.

A teoria do desenho organizacional propõe a combinação de uma estrutura organizacional e de sistemas de controle que permitam à organização perseguir suas estratégias mais eficazmente, isto é, criar e sustentar uma vantagem competitiva. O papel principal de uma estrutura organizacional é, portanto, duplo:

1) coordenar as atividades dos servidores, de tal modo que eles trabalhem em conjunto da maneira mais eficaz possível; e

2) motivar os servidores e providenciar incentivos que lhes permitam alcançar eficiência superior, qualidade, inovação e resposta aos clientes.

Baseado nessa filosofia de reestruturação e fundamentado em teorias de organização, como a de diferenciação e integração, de Lawrence \& Lorsch, e em técnicas de O\&M e de qualidade total, o processo de reestruturação administrativa da DGA foi desenvolvido em pouco mais de três meses, entre maio e agosto de 1995. Após os dois primeiros encontros de planejamento e administração estratégica, tornou-se evidente a necessidade de reestruturação da DGA.

Na realidade, havia não somente uma diretriz do presidente da República no sentido do enxugamento da máquina pública, como também era necessário adequar a estrutura do Palácio do Planalto às novas estratégias delineadas naqueles encontros. O processo procurou rever a organização estrutural, funcional e hierárquica, bem como buscou a racionalização de 
métodos e atividades da DGA para torná-la mais eficiente em cada uma das etapas de funcionamento dos departamentos, e mais eficaz, em relação aos resultados alcançados. Por essa razão, as atividades de reestruturação da DGA já se iniciaram no dia 19 de maio de 1995 com a participação de representantes dos departamentos então existentes (Departamento de Administração, Comunicações, Documentação, Instalações, Orçamento e Finanças, Pessoal, Saúde e Transportes).

A DGA compreendia, portanto, oito departamentos diferentes, cada qual com suas respectivas divisões. Cada departamento foi analisado separadamente, divisão por divisão, especialmente com relação aos seguintes aspectos:

1) organograma atual: levantava o raio de determinada divisão, com todas as suas seções;

2) validação das funções: fornecia os objetivos teóricos de determinada divisão;

3) funções existentes: detalhava o que realmente era feito no dia-adia; e

4) disfunções: fornecia as atividades exercidas incorretamente, por mais de uma divisão ou departamento ou as que representavam desvio dos objetivos centrais daquele departamento.

Ao finalizar esse levantamento, desenvolveu-se nova fase do projeto com o desenho da matriz da estrutura antiga da DGA, a busca de resolução de conflitos e a nova matriz proposta.

\section{A resolução de conflitos e a nova matriz da DGA}

Em artigo publicado em 1997, o autor diz: "As necessidades e objetivos da organização serão sempre diferentes em certo grau das necessidades e objetivos dos seus membros individuais, seus subsistemas e ambientes" (Marcelino, 1997). O artigo mencionava ainda que cada um dos sistemas da organização tem diferentes padrões de referência, pelos quais eles vêem, interpretam e julgam o ambiente, a organização e a informação que obtêm. Essas diferenças são necessárias e funcionais, pois provêem a organização com informações sob diferentes perspectivas. Quando, porém, essas diferenças levam a conflitos, ao invés de colaboração, elas passam a ser disfuncionais e indesejadas. Mecanismos estruturais de integração, para a resolução de diferenças, devem ser adotados. Existem três formas de resolver os conflitos:

a) resolução por meio da negação do conflito;

b) resolução por meio do uso de força; e

c) resolução por confrontação de diferenças. 
Todos esses métodos podem ser eficientes dentro dos limites, mas sua eficácia pode ser julgada com base nos efeitos provocados em todas as partes da organização. A negação do conflito pode torná-lo mais difícil de ser resolvido, pois quanto mais o problema é evitado maior se torna. A força para resolver conflitos provoca efeitos disfuncionais em vários aspectos, pois dá ênfase exagerada ao controle, em detrimento do processamento de informações do ambiente, tendendo a criar sistemas fechados em si mesmos. Assim, a confrontação das diferenças torna-se o método mais eficaz, por meio da negociação aberta entre os indivíduos, até que se alcance a melhor solução para a organização como um todo. Mas é necessário que o sistema de suporte organizacional esteja de acordo com o pacto estabelecido.

No caso da DGA, a matriz elaborada com os dados obtidos na primeira etapa do projeto - detalhamento da estrutura dos departamentos - mostrou claramente as disfunções de cada divisão e departamento. Foi proposta, então, uma nova matriz com o objetivo de corrigir as disfunções reveladas pela matriz antiga e permitir que a DGA respondesse mais prontamente aos estímulos do ambiente em que está inserida (as necessidades e aos objetivos da Presidência da República e, mais precisamente, da SGPR).

A matriz de funções e a nova estrutura da DGA foram desenhadas com a participação direta de funcionários que, voluntariamente, identificaram disfunções na estrutura antiga passíveis de correção, com a preocupação de documentar os levantamentos e proposições, para depois validar a proposta consensada com a equipe e, posteriormente, submetê-la à aprovação dos chefes de cada departamento. Assim, o modelo de confrontação aberta foi utilizado, determinando-se o foco do conflito (a disfunção de cada unidade) o que se confrontaram os aspectos da vida organizacional da DGA.

Nessa fase dos trabalhos, a Diretoria-Geral definiu, como única amarração, os conceitos aprovados nas sessões de planejamento estratégico, e as equipes tiveram total autonomia para realizar os trabalhos em clima de ampla discussão democrática e participação.

\section{O princípio do mínimo de estruturas}

A diferenciação e flexibilidade organizacionais exigem minimizar estruturas, deixando a cargo dos membros da organização a definição dos processos e formas organizacionais que melhor atendam às necessidades de seus respectivos subsistemas. Para que isso ocorra, pressupõe-se que os indivíduos sejam capazes, confiáveis e motivados não precisem ser controlados. Essa filosofia de gestão se fundamenta em teorias de comportamento humano, desenvolvidas por Abraham Maslow, Douglas McGregor, Frederic Herzberg e Chris Argyris. 
Durante todo o processo de reestruturação da DGA, a motivação foi uma das ferramentas adotadas. Foram privilegiadas a delegação de responsabilidades e a cobrança de posturas gerenciais, o treinamento e a capacitação nos níveis técnico, operacional e gerencial. Os funcionários foram chamados a colaborar e o diretor-geral procurou motiválos, diretamente, por meio de instrumentos, como a instituição de incentivos, o reconhecimento nas equipes de trabalho, os elogios em reuniões com a Diretoria-Geral e o destaque público do funcionário. Por meio de treinamentos, provisão dos recursos necessários e adoção de modernos sistemas de informação, os funcionários passaram a ter maior noção de coletividade e maior preocupação com o desenvolvimento de toda a DGA.

As organizações têm vários níveis organizacionais e correspondentes ao grau de responsabilidade e à perspectiva envolvida em cada nível. Cada nível é um subsistema ou supersistema, de acordo com os propósitos em questão. Cada nível sistêmico tem quatro funções gerais:

- tomar decisões de natureza coletiva, que não podem ser feitas adequadamente por um subsistema dentro do sistema, nem precisam ser feitas por um nível sistêmico mais alto. Essas decisões devem afetar mais de um subsistema dentro do nível sistêmico, bem como requerer informações e demandas recursos de mais um subsistemas;

- prover recursos para os seus subsistemas;

- ter responsabilidades e prestar contas em nível sistêmico mais alto; $\mathrm{e}$

- ter uma função coordenadora, em relação aos seus subsistemas.

Com base nesses dados teóricos, podemos avaliar a nova estrutura proposta para a DGA, obtida por meio das duas etapas iniciais (levantamento de dados, matriz antiga e nova matriz proposta).

Alguns critérios foram adotados na reestruturação da DGA, atendendo ao modelo teórico descrito:

- redução de amplitude de comando;

- redução de superposição de funções executadas por várias unidades;

- centralização de funções de natureza semelhante;

- flexibilização administrativa;

- redução do excesso de burocracia;

- fortalecimento da estrutura formal; e

- agilização dos processos decisórios.

Ao final do processo, delineou-se, então, uma nova estrutura organizacional para a DGA, que, comparada com a estrutura anterior, apresentou as seguintes mudanças: 
Quadro 2: Comparação entre a estrutura organizacional anterior e posterior ao processo de planejamento estratégico

\begin{tabular}{l|c|c|c}
\hline & $\begin{array}{c}\text { Estrutura } \\
\text { anterior }\end{array}$ & $\begin{array}{c}\text { Nova } \\
\text { estrutura }\end{array}$ & $\begin{array}{c}\text { Percentual } \\
\text { de redução }\end{array}$ \\
\hline Setores & 117 & 0 & $100 \%$ \\
\hline Seções & 84 & 37 & $56 \%$ \\
\hline Divisões & 48 & 24 & $50 \%$ \\
\hline Departamentos & 8 & 4 & $50 \%$ \\
\hline Total & 257 & 65 & $75 \%$ \\
\hline
\end{tabular}

\section{Considerações finais}

A teoria das organizações concebe as organizações como sistemas, isto é, um conjunto cujas partes estão em tal estado de interdependência que mudanças em uma parte da organização tendem a produzir mudanças em outras partes. A escolha do modelo mais adequado de planejamento e estruturação de uma organização é necessariamente contingencial e depende do ambiente, da natureza da atividade e da tecnologia, dos objetivos e estratégias da organização e das pessoas envolvidas. Não existe um modelo ideal que funcione em todas as situações, em todas as culturas e com todos os tipos de pessoas. Conforme dizem os autores da teoria contingencial, "it all depends".

O desenvolvimento da teoria organizacional e das técnicas do planejamento estratégico possibilita atender às solicitações da sociedade por maior eficácia e eficiência na gestão organizacional, especialmente no caso da gestão pública. Foi o que se buscou com o processo de planejamento e administração estratégica da DGA/SGPR.

Os quadros 1 e 2 deste estudo demonstram alguns dos resultados obtidos no atingimento de metas, projetos e programas e no cumprimento dos objetivos e da missão da DGA. De um percentual de $81,2 \%$ de cumprimento das metas previstas em 1996, chegou-se a 91,3\% em 1998. De um total de 257 unidades existentes em abril de 1995, quando se iniciou o processo de reestruturação, restaram 65 unidades administrativas, no final do primeiro ano de execução, processo com redução de $75 \%$ das unidades básicas da estrutura administrativa.

Como resultado final desse processo de planejamento estratégico e reestruturação da DGA, o quadro de servidores foi reduzido de 1.187, em janeiro de 1995, para 742 servidores, em dezembro de 1998, uma redução de $37 \%$ do efetivo de pessoal. E o que é melhor: sem grandes traumas ou problemas sociais, na medida em que, não tendo a Presidência da República 
quadro permanente, os servidores dispensados foram devolvidos a seus órgãos de origem.

Um outro indicador demonstra os ganhos de qualidade e produtividade no período: desde 1996, a DGA passou a ser o órgão líder de execução orçamentária na Esplanada dos Ministérios, atingindo 99,5\% de execução do orçamento fiscal de 1998 contra uma média dos demais ministérios na faixa de $87 \%$.

Esse processo permitiu ainda melhorar, substantivamente, a qualidade nas atividades desenvolvidas, uma distribuição da força de trabalho mais adequada, apesar da redução dos efetivos de pessoal, e uma estrutura mais compatível com as demandas. Em termos de redução de custos, conforme já mencionado, a economia chegou a $\mathrm{R} \$ 16,8 \mathrm{mi}-$ lhões/ano com pessoal e a $\mathrm{R} \$ 9,70$ milhões/ano com a adoção de programa de terceirização.

Em dezembro de 1998, novos desafios foram discutidos e acordados entre os participantes do VI Encontro de Planejamento e Administração Estratégica da DGA. Dentre eles, destacam-se os seguintes:

- manter as conquistas e ampliar os resultados;

- maximizar os recursos existentes;

- conviver com o orçamento decrescente;

- manter o patamar tecnológico;

- manter o foco nos recursos humanos;

- estar preparado para o novo período de governo; e

- dar continuidade ao processo de planejamento e administração estratégica.

O trabalho, pioneiro, desenvolvido na SGPR e DGA certamente inspirou o novo governo que se iniciou em janeiro de 1999 a contratar empresa de consultoria para repensar a estrutura do Palácio do Planalto como um todo, estendendo esse tipo de processo à Casa Civil e à Casa Militar. A informação de que dispomos é de que a nova direção da DGA, atualmente Secretaria de Administração da Casa Civil, pretende dar continuidade ao processo de planejamento e administração estratégica do órgão.

No caso específico em análise, da DGA do Palácio do Planalto, podese afirmar que os novos modelos propostos de administração estratégica e reestruturação administrativa objetivaram adaptar os modernos conceitos de gestão, diferenciação e integração a uma instituição dinâmica, que busca a excelência dos serviços prestados e interage com o seu ambiente de forma a motivar seu pessoal e a si mesma, dentro do processo de reforma do Estado. Aliás, esse processo de planejamento estratégico e reestruturação organizacional desenvolvido no Palácio do Planalto, centro do processo decisório do Poder Executivo, constituiu-se em trabalho pioneiro e efetivo de implementação da reforma do Estado, proposto pelo Ministério da Administração e Reforma do Estado (Mare) e desenvolvido no primeiro mandato (1995-1998) do governo Fernando Henrique Cardoso. 
${ }^{1}$ Em 1o de janeiro de 1999, por intermédio da Medida Provisória oㅜ 1.799, a estrutura administrativa dos órgãos componentes da Presidência da República foi alterada, com a extinção da SGPR e a transferência de suas funções e atribuições para a Casa Civil. Evidentemente, as atribuições da DGA foram preservadas, porque necessárias ao funcionamento do Palácio do Planalto. A Diretoria-Geral de Administração foi transformada em Secretaria de Administração, vinculada diretamente à Casa Civil. 


\section{Referências bibliográficas}

Ackoff, Russel L. (1980), Planejamento Empresarial. São Paulo: Livros Técnicos e Científicos.

Ansoff, H. Igor.(1989), A Nova Estratégia Empresarial. São Paulo: McGraw-Hill. . (1993), Implantando a Administração Estratégica. São Paulo: Editora Atlas.

BENNIS, Warren. (1989), Mudanças Organizacionais. São Paulo: Atlas.

Bethlen, Agrícola de Souza. (1989), Gerência à Brasileira. São Paulo: McGraw-Hill.

Degen, Ronald. (1989), O Empreendedor: fundamentos da iniciativa empresarial, São Paulo: McGraw-Hill.

GAJ, Luís. (1987), Administração Estratégica. São Paulo: Ática.

Hill, Charles; Jones, Gareth. (1995), Strategic Management - An Integrated Approach. 3- Edition, Boston: Houghton Mifflin Company.

LAwrence, Paul R., Lorsch, Jay W. (1993), A organização e ambiente. São Paulo: Vozes. . (1972), O desenvolvimento de organizações: diagnóstico e ações. São Paulo: Blüche.

Marcelino, Gileno F. (1985), Diferenciação e Integração: o Conceito de Adaptabilidade Organizacional in Descentralização em Ciência e Tecnologia. São Paulo: Cortez. . (1997), Teoria das Organizações. Brasília: UnB. . (2000), Como planejar e estruturar uma organização a partir da Administração Estratégica. Mimeo, CAC/UnB.

McGregor, Douglas. (1960), The Human Side of Enterprise. Nova Iorque: McGrawHill.

Porter, M.E. (1989), Vantagem Competitiva: criando e sustentando um desempenho superior. Rio de Janeiro: Campus.

Presidência da República. (1995), Projeto de Reorganização da Diretoria-Geral de Administração. Brasília: Diretoria de Modernização e Informática. 
Revista do

Serviço

Público

Ano 53

Número 4

Out-Dez 2002

Gileno Fernandes

Marcelino é

professor da

Universidade de

Brasília (UnB);

professor

visitante da

J.L.Kellogg

Graduate Schoo

of Management

da Northwestern

University;

professor

associado da

Universidade de

São Paulo;

consultor de

processos de

reestruturação

administrativa e

planejamento

estratégico em

organizações

públicas e

privadas; e,

atualmente, é

diretor da

Faculdade de

Estudos Sociais da

UnB.

Contato:

gmarcel@

solar.com.br

\section{Resumo \\ Resúmen \\ Abstract}

\section{Planejamento estratégico no setor público: uma experiência no Palácio do Planalto}

Gileno Fernandes Marcelino

Este trabalho descreve e analisa uma experiência pioneira de desenvolvimento de um processo de planejamento e administração estratégica no Palácio do Planalto, centro de decisões do Poder Executivo. O processo, que se iniciou em março de 1995, primeiro ano de mandato do atual presidente, prossegue até os dias de hoje, como exemplo raro de continuidade administrativa na Administração Pública Federal.

Nestes quatro anos de experiência, a Secretaria-Geral da Presidência da República (SGPR) alcançou alguns resultados concretos: 98,5\% de execução orçamentária (um recorde na Esplanada dos Ministérios), 91,3\% das ações, metas, projetos e programas executados, redução do pessoal e estrutura administrativa em mais de 50\% e uma economia estimada em mais de R \$ 100 milhões durante os quatro anos. Este estudo descreve como tudo isso foi alcançado.

\section{Planificación estratégica en el sector público: una experiencia en el Palacio del Planalto \\ Gileno Fernandes Marcelino}

El presente trabajo describe y analiza una experiencia pionera de desarrollo de un proceso de Planificación y Administración Estratégica en el Palacio del Planalto, centro de decisiones del Poder Ejecutivo. El proceso, iniciado en Marzo de 1995, primer año de mandato del actual presidente, prosigue hasta los días de hoy, como un ejemplo raro de continuidad administrativa en la Administración Pública Federal.

En esos cuatro años de experiencia, la Secretaría General de la Presidencia de la República (SGPR) alcanzó algunos resultados concretos: el 98,5\% de ejecución presupuestaria (un record en Esplanada de los Ministerios), el 91,3\% de las acciones, metas, proyectos y programas ejecutados, reducción del personal y estructura administrativa de más del 50\% y una economía estimada en más de R $\$ 100$ millones durante los cuatro años. El presente estudio describe como se alcanzó todo eso.

\section{Strategical planning in the public sector: an experience in the Planalto Palace Gileno Fernandes Marcelino}

This paper describes and analyses a strategic management process, a pioneer experience developed in the Palácio do Planalto, the brazilian executive power decision-making center. The process was initiated in March, 1995, the first year of the actual president mandate, and continues up to date as a rare example of administrative continuity in Public Management Service.

In this four-year experience, the General Secretariat of the Presidency of the Republic reached some concrete results: $98,5 \%$ of budget execution - a record among the ministries, $91,3 \%$ of targets, projects and programs executed, $50 \%$ of personnel downsizing and administrative reestructuration and a reduction of the bureaucratic costs of over $\mathrm{R} \$ 100$ million in this period. This paper describes how these targets were successfully accomplished. 